\title{
TREATMENT COAGULANT AID DAN FILTRASI MANGANESE GREENSAND DALAM MENURUNKAN KADAR MANGAN DAN KLORIDA
}

\author{
Rossy Rosfianto ${ }^{1)}$, dan Setyo Purwoto ${ }^{1)}$ \\ ${ }^{1)}$ Program Studi Teknik Lingkungan Fakultas Teknik Sipil dan Perencanaan \\ Universitas PGRI Adi Buana Surabaya \\ email: rossyariant22@gmail.com
}

\begin{abstract}
Abstrak
Di daerah Kalanganyar banyak warga yang menggunakan air sumur gali yang terkontaminasi air asin sehingga menjadi air payau. Tujuan dari penelitian ini yaitu mengetahui Efektifitas Pemakaian kadar ppm Sucolite dipadukan dengan ketinggian media Manganese Greensand, Ferrolite, Karbon Aktif dan Resin Kation Anion dalam Menurunkan kadar Mangan (Mn) dan Klorida $\left(\mathrm{Cl}^{-}\right)$pada Air Sumur Gali Didesa Kalanganyar. Salah satu alternatif pengolahan air payau yakni menggunakan perpaduan koagulasi mengunakan koagulan Sucolite dan filtrasi dengan media Ferrolite, Manganese Greensand, Karbon Aktif dan Resin Kation Anion. Menggunakan variasi Kadar ppm Sucolite Sp 211 (30, 50, dan 70 ppm) dan Ketinggian Manganese Greensand $(30 \mathrm{~cm}$ dan $60 \mathrm{~cm})$. Treatment perpaduan kadar ppm Sucolite dan ketinggian media filtrasi manganese greensand dapat menurunkan kadar logam Mangan (Mn) hingga $<0,0294 \mathrm{mg} / \mathrm{L}$, Klorida $\left(\mathrm{Cl}^{-}\right)$hingga $350,10 \mathrm{mg} / \mathrm{L}$. secara signifikan penurunan paling optimal yaitu pada kadar Sucolite 50 ppm dan ketinggian media manganese greensand $30 \mathrm{~cm}$.
\end{abstract}

Kata Kunci: Air Tanah, Filtrasi, Koagulasi

\begin{abstract}
In the Kalanganyar area many people use dug well water contaminated with salt water so that it becomes brackish water. The purpose of this research is to find of effectiveness of using ppm levels of Sucolite is combined with the height of the media Manganese Greensand, Ferrolite, Activated Carbon and Cation Anion Resins in Reducing Iron (Fe), Manganese (Mn) and Chloride (Cl-) in Wells Water In Kalanganyar. One alternative is brackish water treatment using a combination of coagulation using Sucolite and filtration with Ferrolite, Manganese Greensand, Activated Carbon and Cation Anion media. Using variations in levels of ppm Sucolite Sp 211 (30, 50 and 70 ppm) and Altitude of Manganese Greensand (30 cm and $60 \mathrm{~cm}$ ). Treatment of a combination of Sucolite ppm levels and the height of the manganese greensand filtration media can reduce the metal content of Manganese (Mn) to <0.0294 $\mathrm{mg} / \mathrm{L}$, Chloride (Cl-) to $350.10 \mathrm{mg} / \mathrm{L}$. the most optimal decrease was at the level of Sucolite $50 \mathrm{ppm}$ and the height of the media manganese greensand was $30 \mathrm{~cm}$.
\end{abstract}

Keyword: Groundwater, Filtration, Coagulation 


\section{PENDAHULUAN}

Pengertian air bersih untuk keperluan Higiene Sanitasi menurut Peraturan Menteri Kesehatan Republik Indonesia Nomor 32 Tahun 2017 adalah air dengan kualitas tertentu yang digunakan untuk keperluan sehari-hari yang kualitasnya berbeda dengan kualitas air minum, air baku permukaan, air tanah dan air laut.

Pada umumnya air tanah mempunyai kualitas yang cukup baik, dan apabila dilakukan pengambilan yang baik dan bebas dari pengotoran dapat dipergunakan langsung. Air tanah adalah segala bentuk aliran air hujan yang mengalir dibawah permukaan tanah sebagai akibat struktur perlapisan geologi, beda potensi kelembapan tanah, dan gaya gravitasi bumi. Air bawah permukaan tersebut bisa dikenal dengan air tanah (Asdak, 2002).

Teknologi yang digunakan dalam menurunkan konsentrasi Mangan (Mn) dan Klorida (Cl-) yaitu menggunkan teknologi koagulasi dan filtrasi. Berdasarkan penelitian pendahuluan nilai kadar mangan sebesar $1,24 \mathrm{mg} / \mathrm{L}$, dan untuk Klorida adalah sebesar 1439 $\mathrm{mg} / \mathrm{L}$. Sedangkan nilai ambang batas yang diperbolehkan menurut Peraturan Menteri Kesehatan Republik Indonesia Nomor 32 Tahun 2017 untuk keperluan hygiene sanitasi yaitu kadar Logam Mangan $0,5 \mathrm{mg} / \mathrm{L}$, dan kadar Klorida $600 \mathrm{mg} / \mathrm{L}$.

Nurhayati. (2006), menjelaskan pada penelitiannya yang berjudul "Desalinasi Air Payau Dengan Membran Reverse Osmosi (RO) Tekanan Rendah" bahwa sampel air yang terdapat pada pesisir Sidoarjo Jawa timur Indonesia menunjukkan kadar klorida $8580 \mathrm{mg} / \mathrm{L}$.

Salah satu temuan dalam hal penurunan parameter air bersih yang dilakukan dengan menggunakan treatment Coagulant Aid, Pasir Silika, Ferrolite, Manganese Greensand, Resin Sintetis (kation anion), dan membrane RO diperoleh hasil penurunan parameter air bersih khlorida 292,878 $\mathrm{mg} / \mathrm{L}$, Mangan 1,235 mg/L (Purwoto et al., 2018).
Tujuan dalam penelitian ini untuk mengetahui Efektifitas Pemakaian kadar ppm Sucolite dipadukan dengan ketinggian media Manganese Greensand, Ferrolite, Karbon Aktif dan Resin Kation Anion dalam Menurunkan kadar Mangan (Mn) dan Klorida $\left(\mathrm{Cl}^{-}\right)$ pada Air Sumur Gali Didesa Kalanganyar. Sucolite dalam penelitian ini berperan dalam pengikatan partikelpartikel halus yang tidak dapat diendapkan secara gravitasi, menjadi partikel yang lebih besar sehingga bisa diendapkan dengan jalan menambahkan bahan koagulasi (dalam penelitian ini menggunakan sucolite dengan variasi 30 ppm, 50 ppm dan 70 ppm).

Manganese Greensand adalah pasir khusus yang dilapisi dengan bahan katalis. Manganese Greensand merupakan absorben untuk menurunkan kadar besi dan mangan pada air. Dimana reaksi dari $\mathrm{Fe} 2+$ dan $\mathrm{Mn} 2+$ dalam air dengan oksida mangan tinggi (higher mangan oxide) menghasilkan filtrat yang mengandung ferri-oksida dan mangan-oksida yang tidak dapat larut dalam air dan dapat dipisahkan dengan pengendapan dan penyaringan. Removal $\mathrm{Mn}^{2+}$ dapat dilakukan dengan adsorbs oleh Mangan oksida dalam manganese oxide coated zeolite (MOCZ) (Taffarel, 2010). Dalam penelitian ini Manganese Greensand dimasukkan dalam pipa berdiameter 4 inchi dengan ketinggian 11,8 inchi dan 23,6 inchi sebagai media filtrasi.

Fungsi Ferrolite dalam penelitian ini adalah untuk meenghilangkan kandungan Mangan $\left(\mathrm{Mn}^{+}\right)$, dan warna kuning di air tanah (Purwoto, S., 2016) Resin merupakan suatu polimer yang terbuat dari polystyrene dengan divinil benzene sebagai cross link. Resin dibagi menjadi 2 jenis yaitu:

\section{$1 . \quad$ Resin Kation}

Melepas ion positif pada resin (misalnya $\mathrm{H}^{+}$atau $\mathrm{Na}^{+}$) untuk ditukar dengan kandungan unsur kation pada air.

2. Resin Anion

Melepas ion negatif pada resin (misalnya $\mathrm{OH}^{-}$atau $\mathrm{Cl}^{-}$) untuk ditukar 
dengan kandungan unsur anion pada

air. Purwoto, S. (2009) menyimpulkan bahwa desalinasi air payau dapat dilakukan secara ion exchange dengan treatmen pasangan resin sintetis kation dan anion baik terpisah maupun secara campuran keduanya. Penggunaan Sedimen Poly Propilena (SPP) sebagai penyaring air dari kandungan lumpur, pasir, tanah dan partikel kotoran zat padat terlarut air lainnya sehingga menghasilkan air jernih, bersih bebas dari pencemaran zat padat terlarut dalam air. Sediment Polypropylene mempunyai removal ratings: 0.2 ,0.45, 1, 5, 10, 20, $50 \mu \mathrm{m}$. Dengan suhu maksimum $82{ }^{\circ} \mathrm{C}$, dan rekomendasi tekananya adalah 35 psig (Nurhayati, 2014).

Untuk meningkatkan kebutuhan dasar masyarakat mengenai kebutuhan air bersih tersebut, maka perlu disesuaikan teknologi yang sesuai dengan tingkat penguasaan teknologi dalam masyarakat itu sendiri. Salah satu alternative yakni dengan menggunakan teknologi Pengolahan air sederhana berbasis treatment Coagulantaid, Ferrolite, Manganese Greensand, karbon Aktif dan Resin kation Anion.

Mengacu pada penelitian (Nurhayati, 2014), penurunan parameter sesuai dengan kebutuhan air bersih oleh pengaruh techno membran RO dikombinasikan dengan bantuan koagulan dan penukar ion tercapai pada parameter; klorida, kekeruhan, warna, besi, total disolved solid (TDS), total kekerasan, Bahan Organik, Fluorida, Nitrat, Nitrit, Seng, Sulfat, dan Deterjen
METODE

Rancangan pada penelitian ini diawali dengan pengambilan air baku, kemudian dilakukan pengolahan menggunakan Koagulan Sucolite SP 211 kemudian dilanjutkan dengan filtasi Manganese Greensand selanjutnya dialirkan menuju 4 housing filter yang sudah diberi media yang berdeda yaitu, Ferolite, Resin kation, Resin Anion dan Karbon Aktif. Populasi penelitian ini adalah Air sumur gali rumah warga di RT 21 RW 05 Desa Kalanganyar Kecamatan Sedati Sidoarjo. Penelitian ini dilakukan di Laboratorium Rekayasa teknik lingkungan Universitas PGRI Adi Buana Surabaya.

Alat dan bahan yang digunakan:

a) Bahan reaktor yang digunakan catridge filter housing. Fungsi housing filter adalah untuk menempatkan cartridge filter (katrid filter)

b) Untuk memudahkan setting dan efisiensi aliran, pipa yang digunakan PVC

c) Pompa supplay menggunakan submersible-pump

d) Succolite SP 211

e) Manganese Greensand untuk menghilangkan kandungan Mangan $\left(\mathrm{Mn}^{2+}\right)$, dan lapisan atas berminyak di dalam air sebagai katalis dan pada waktu yang bersamaan besi dan mangan yang ada dalam air teroksidasi menjadi bentuk ferrioksida dan mangandioksida yang tak larut dalam air. 


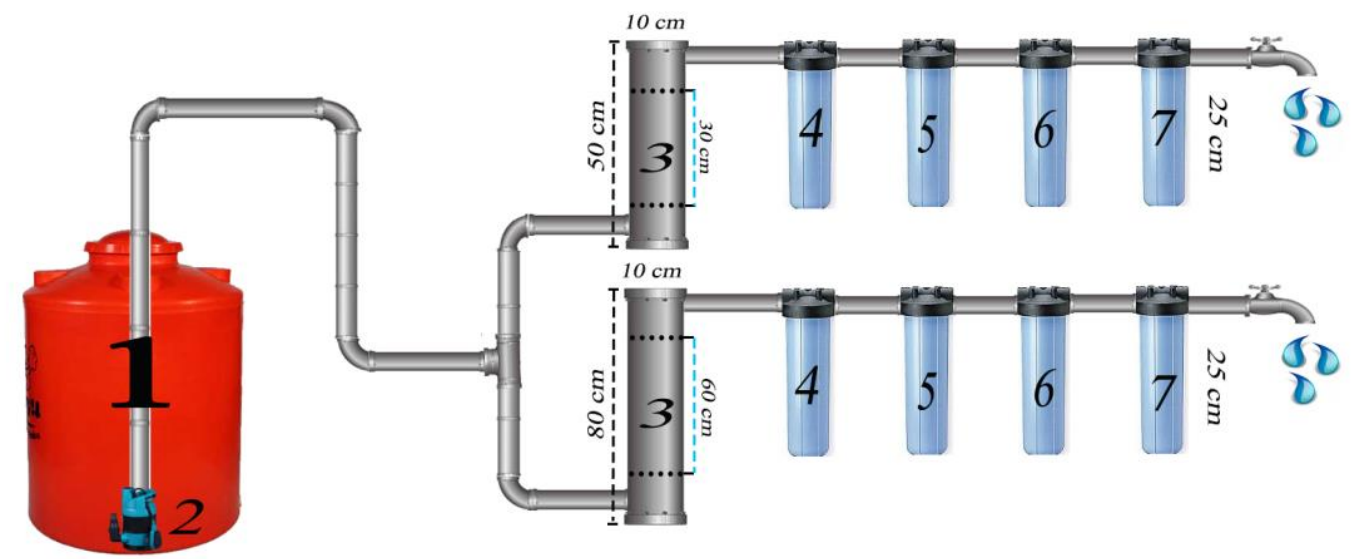

Gambar 1 Instalasi Pengolahan

Keterangan :

1. Bak Koagulasi

2. Pompa

3. Treatment dengan media Manganese Grensand

4. Housing filter dengan media Ferrolite

5. Housing filter dengan media resin anion

6. Housing filter dengan media resin Kation

7. Housing filter dengan media resin karbon aktif

Prosedur Penelitian

a. Memastikan semua perpipaan telah terpasang dengan baik

b. Sampel Air Tanah yang berwadah Jurigen ditampung ditandon air baku

c. Dalam tandon dicampurkannya air baku dengan koagulan sucolite $\mathrm{Sp}$ 211 dengan variasi ppm yang sudah ditentukan.

d. Mengalirkan air menuju reactor yang berisi manganese greensand dengan ketinggian media yang sudah ditentukan

e. Sampel melewati reactor manganese grensand

f. Sampel melewati empat housing filter dengan media yang berbeda, yang pertama housing filter dengan media Ferrolite, kedua dengan media resin anion, ketiga dengan media resin kation dan yang terakhir dengan media karbon aktif.

g. Sampel siap disampling pada pengambilan sampel effluent dari masing masing variasi treatmen yang sudah ditentukan. Kemudian dilakukan pengulangan sebanyak 1 hari 2 kali pengambilan selama 5 hari berturut turut.

h. Memberi label pada masing-masing sampel

i. Sampel hasil treatment akan diuji dilaboratorium untuk mengetahui evektifitas removal logam Mangan (Mn) dan Klorida $\left(\mathrm{Cl}^{-}\right)$.

Coagulant Aid yang digunakan dalam penelitin ini adalah Sucolite SP 211 berupa cairan tidak berwarna dan tidak berbau. Filtrasi menggunakan media Manganese Greensand dan dimasukkan kedalam tabung filter yang terbuat dari PVC 4"yang telah divariasikan dengan ketinggian $30 \mathrm{~cm}$ dan $60 \mathrm{~cm}$. Sedangkan perlakuan Ferrolite, resin anion dan kation dan Carbon Block dilakukan dalam housing filter.

Definisi Operasional Variabel

a. Pada penelitian ini penurunan kadar Mangan (Mn) dan Klorida $\left(\mathrm{Cl}^{-}\right)$ dilakukan dengan metode perpaduan koagulasi dan filtrasi.

b. Sucolite SP 211

Sucolite dalam penelitian ini berperan dalam pengikatan partikelpartikel halus yang tidak dapat diendapkan secara gravitasi, menjadi partikel yang lebih besar sehingga bisa diendapkan dengan jalan menambahkan bahan koagulasi (dalam penelitian ini menggunakan 
sucolite dengan variasi $30 \mathrm{ppm}, 50$ ppm dan 70 ppm).

c. Manganese Greensand

Manganese Greensand adalah pasir khusus yang dilapisi dengan bahan katalis. Manganese Greensand merupakan absorben untuk menurunkan kadar besi dan mangan pada air. Dimana reaksi dari $\mathrm{Fe} 2+$ dan $\mathrm{Mn} 2+$ dalam air dengan oksida mangan tinggi (higher mangan oxide) menghasilkan filtrat yang mengandung ferri-oksida dan mangan-oksida yang tidak dapat larut dalam air dan dapat dipisahkan dengan pengendapan dan penyaringan. Dalam penelitian ini Manganese Greensand dimasukkan dalam pipa berdiameter 4 inchi dengan ketinggian 11,8 inchi dan 23,6 inchi sebagai media filtrasi.

d. Ferrolite

Fungsi Ferrolite dalam penelitian ini adalah untuk meenghilangkan kandungan besi tungkat tinggi $(\mathrm{Fe})$, bau besi yang menyengat Mangan $\left(\mathrm{Mn}^{+}\right)$, dan warna kuning di air tanah (Purwoto, S., 2016)

e. Resin

Resin merupakan suatu polimer yang terbuat dari polystyrene dengan divinil benzene sebagai cross link. Resin dibagi menjadi 2 jenis yaitu :
1. Resin Kation

Melepas ion positif pada resin (misalnya $\mathrm{H}^{+}$atau $\mathrm{Na}^{+}$) untuk ditukar dengan kandungan unsur kation pada air.

2. Resin Anion

Melepas ion negatif pada resin (misalnya $\mathrm{OH}^{-}$atau $\mathrm{Cl}^{-}$) untuk ditukar dengan kandungan unsur anion pada air.

Dalam penelitian ini resin difungsikan untuk menurunkan kadar salinitas yang terkandung dalam air sumur desa Kalanganyar.

f. Karbon Aktif

Permukaan karbon aktif bersifat nonpolar sehingga lebihmudah melakukan penyerapan warna, bau, dan mengurangi jumlah peroksida sehingga memperbaiki mutu minyak (Utari, W.). Dalam enelitian ini karbon aktif berfungsi untuk mengurangi kadar warna.

Metode Analisa Data

Data yang terkumpul dalam penelitian ini dipilah berdasarkan kategorinya, kemudian akan diolah dalam bentuk tabulasi. Perhitungan efektivitas ramoval kadar logam Mangan (Mn) dan Klorida $\left(\mathrm{Cl}^{-}\right)$di hitung menggunakan rumus sebagai berikut ini:

$$
\% R=\left\{1-\frac{C p}{C f}\right\} \times 100
$$

$\% \mathrm{R}=$ Efektivitas Removal $(\%)$

$\mathrm{Cp}=$ konsentrasi outlet atau setelah treatment $(\mathrm{mg} / \mathrm{L})$

$\mathrm{Cf}=$ konsentrasi inlet atau sebelum treatment $(\mathrm{mg} / \mathrm{L})$

\section{HASIL DAN PEMBAHASAN}

Sampel air baku setelah dilakukan treatment Sucolite SP 211 sebagai Coagulant Aid pada tanki koagulan, kemudian treatment filtrasi menggunakan Manganese Greensand pada pipa PVC. Selanjutnya berturut turut treatment; Ferrolite, Resin anion kation dan Carbon Block pada housing filter diperoleh data sebagaimana disajikan sebagai berikut.

\section{a. Hasil Uji Mn Sebelum dan Setelah Treatment}

Mn merupakan unsur logam golongan VII. Mn dalam air dapat menimbulkan bau dan rasa yang tidak sedap (Said, 2011). Tabel analisis data konsentrasi Mn akan disajikan dalam tabel 1 . 
Tabel 1. Data Hasil Uji Laboratorium Parameter Mn

\begin{tabular}{ccccccc}
\hline \multirow{2}{*}{ Hari Ke- } & $\mathrm{R} 1$ & $\mathrm{R} 2$ & $\mathrm{R} 3$ & $\mathrm{R} 4$ & $\mathrm{R} 5$ & $\mathrm{R} 6$ \\
\hline Inlet & 0,524 & 0,524 & 1,03 & 1,03 & 1,137 & 1,137 \\
1 & 0,0532 & 0,0432 & 0,0905 & 0,065 & 0,0294 & 0,0802 \\
2 & 0,0294 & 0,0297 & 0,058 & 0,0435 & 0,0372 & 0,0452 \\
3 & 0,0294 & 0,0294 & 0,0695 & 0,0845 & 0,2575 & 0,217 \\
4 & 0,0294 & 0,0294 & 0,0262 & 0,0435 & 0,3655 & 0,2995 \\
5 & 0,0294 & 0,0294 & 0,0294 & 0,0865 & 0,331 & 0,269 \\
\hline
\end{tabular}

(Sumber : Hasil Analisis di Balai Riset dan Standarisasi Industri Surabaya, 2019.)

Keterangan:*) dalam satuan $\mathrm{mg} / \mathrm{L}$.

Dari tabel 2 di atas dapat dilihat bahwa penurunan kadar Mn paling tinggi dihasilkan dari Reaktor 3 yang mampu menurunkan kadar $\mathrm{Mn}$ rata rata sebesar $94 \%$, penurunan tertinggi yaitu pada hari ke 4 dengan kadar Mn sebelum treatment yaitu $1.03 \mathrm{mg} / \mathrm{L}$. Setelah mengalami treatment menjadi $0,0262 \mathrm{mg} / \mathrm{L}$. Sedangkan penurunan kadar Mn paling rendah dihasilkan dari Reaktor 5 yang mampu menurunkan kadar Mn rata rata sebesar $82 \%$, penurunan terendah yaitu pada hari ke 4 dengan kadar $\mathrm{Mn}$ sebelum treatment yaitu $1.137 \mathrm{mg} / \mathrm{L}$. Setelah mengalami treatment menjadi $0,2995 \mathrm{mg} / \mathrm{L}$. hasil yang didapatkan mengalami fluktuatif, hal itu disebabkan banyak hal, salah satunya gangguan aliran pada reactor seperti kebocoran pada instalasi.

Perbandingan data menurut penelitian Al Kholif (2018). Menyatakan bahwa treatment menggunakan Coaguland Aid, Sediment Polypropylene, dan Manganese Greensand mampu menurunkan kadar Mn sebesar 1,52 mg/L. Sedangkan pada penelitian Rahmawati (2015) menyatakan bahwa media filtrasi manganese greensand dan zeolit mampu menurunkan kadar Mn hingga 0,049 $\mathrm{mg} / \mathrm{L}$. Mengacu pada temuan Rachmah, N dan Purwoto, S (2014) filter zeolit alam Manganese Green Sand dan zeolit teraktivasi dengan pemanasan, diperoleh penurunan kandungan $\mathrm{Mn}$ rata-rata sebesar $0,099 \mathrm{mg} / \mathrm{L}$ dari $2,53 \mathrm{mg} / \mathrm{L}$. terdapat perbedaan kemampuan removal $\mathrm{Mn}$ dengan penelitian tersebut karena adanya perbedaan perlakuan. Dalam hal ini dapat diakatakan bahwa filtrasi Manganese Greensand mampu menurunkan kadar Mn dengan baik tanpa mengalami kejenuhan dalam treatmentnya.

\section{b. Hasil Uji $\mathrm{Cl}^{-}$Sebelum dan Setelah Treatment}

Dalam penelitian yang telah dilakukan selama 5 hari, konsentrasi $\mathrm{Cl}^{-}$pada air tanah Desa Kalanganyar Kecamatan Sedati Kabupaten Sidoarjo mengalami fluktuasi disetiap treatmentnya. ananlisis data konsentrasi $\mathrm{Cl}^{-}$akan disajikan dalam tabel 2.

Tabel 2. Analisis Data Konsentrasi $\mathrm{Cl}^{-}$Hasil Penelitian

\begin{tabular}{ccccccc}
\hline \multirow{2}{*}{ Hari Ke- } & $\mathrm{R} 1$ & $\mathrm{R} 2$ & $\mathrm{R} 3$ & $\mathrm{R} 4$ & $\mathrm{R} 5$ & $\mathrm{R} 6$ \\
\hline Inlet & 642,11 & 642,11 & 2659,93 & 2659,93 & 2257,43 & 2257,43 \\
1 & 1252,67 & 1107,91 & 350,10 & 392,02 & 1452,2 & 1639,36 \\
2 & 1245,24 & 1247,19 & 1017,03 & 1208,11 & 1425,08 & 1513,84 \\
3 & 1258,23 & 1208,13 & 1432,48 & 1463,31 & 1358,52 & 1380,69 \\
4 & 1228,54 & 1260,09 & 1393,03 & 1430,02 & 1439,88 & 1417,69 \\
5 & 1217,41 & 1184 & 1395,5 & 1391,8 & 1388,10 & 1400,43 \\
\hline
\end{tabular}

(Sumber : Hasil Analisis di Balai Riset dan Standarisasi Industri Surabaya, 2019)

Keterangan:*) dalam satuan $\mathrm{mg} / \mathrm{L}$ 
Pada Tabel 3 hasil analisis data konsentrasi untuk parameter $\mathrm{Cl}^{-}$. Dari tabel 3 di atas dapat dilihat bahwa penurunan kadar $\mathrm{Cl}^{-}$paling tinggi dihasilkan dari Reaktor 3 yang mampu menurunkan kadar $\mathrm{Cl}^{-}$rata rata sebesar $58 \%$, penurunan tertinggi yaitu pada hari ke 4 dengan kadar Mn sebelum treatment yaitu $2659.93 \mathrm{mg} / \mathrm{L}$. Setelah mengalami treatment menjadi 350,10 mg/L. Sedangkan penurunan kadar $\mathrm{Cl}^{-}$ paling rendah dihasilkan dari Reaktor 1dan 2 yang tidak mampu menurunkan kada $\mathrm{Cl}^{-}$, dapat dilihat dengan adanya kenaikan kadar $\mathrm{Cl}^{-}$setelah dilakukannya pengolahan, hal ini karenakan pada kadar rendah treatment tidak bisa meremoval kadar $\mathrm{Cl}^{-}$dengan baik.

Perbandingan data menurut Apriani (n.d) penurunan kadar klorida menggunakan resin penukar ion mampu menurunkan hingga $22,49 \mathrm{mg} / \mathrm{L}$ dalam penelitian ini penurunan Cl-lebig baik dibandingkan dengan menggunakan Coaguland aid dan filtrasi manganese greensand hal ini dikarenakan media resin mampu menurunkan kadar $\mathrm{Cl}^{-}$ berbeda dengan media manganese greensand yang kurang mampu meremova lkadar $\mathrm{Cl}^{-}$. Pada penelitian oleh (Nurhayati, I., \& Purwoto, S. 2014) yaitu menggunakan perpaduan treatment Coagulant Aid, filtrasi Sediment Polypropylene (SPP), Manganese Greensand, dilanjutkan dengan Ion
Exchanger, dan membran RO yang mampu menurunkan kadar $\mathrm{Cl}^{-} 884 \mathrm{mg} / \mathrm{L}$ sebelum treatment hingga $88 \mathrm{mg} / \mathrm{L}$ setelah treatment. Dalam penelitian sebelumnya mampu menurunkan kadar $\mathrm{Cl}^{-}$dngan baik dikarenakan dilakukannya pengolahan lanjutan menggunakan Reserve Osmosis (RO). Penyisihan kadar $\mathrm{Cl}^{-}$lebih maksimal karena adanya treatment menggunakan Reverse Osmosis. Reverse Osmosis memiliki membran semi permeabel yang dapat menyisihkan kadar $\mathrm{Cl}^{-}$yang tidak dapat dihilangkan pada treatment sebelumnya

\section{KESIMPULAN}

Penggunaan Coagulant Aid dan Filtrasi Manganese Greensand pada air payau daapat menurunkan kadar Mangan (Mn) hingga 0,-294 mg/L (95\%). Sedangkan Klorida $\left(\mathrm{Cl}^{-}\right)$hingga $350,10 \mathrm{mg} / \mathrm{L} \quad(58 \%)$ bada ketebalan media filtrasi Manganese Greensand 30 $\mathrm{cm}$ dimana sucolite sebagai coagulant aid yang digunakan berkada $50 \mathrm{ppm}$.

\section{UCAPAN TERIMAKASIH}

Ucapan terimakasih disampaikan kepada Kepala Laboratorium Teknik Lingkungan. yang telah banyak membantu dalam penelitian dan memfasilitasi dalam penggunaan alat pengolahan air maupun biaya.

\section{DAFTAR PUSTAKA}

Al Kholif, M., Ma'fuddin, Y, T., Widyastuti, S. (2018). “Tingkat Penyisihan Cemaran Air Sungai Menggunakan Coaguland Aid, Sediment Polypropylene, dan Manganese Greensand." Jurnal Teknik WAKTU- ISSN: 1412-1867, 16(1), 1-8.

Apriani, S, R. dan Wesen, P. (n.d). "Penurunan Salinitas Air Payau Dengan Menggunakan Resin Penukar Ion". Skripsi. Universitas Pembangunan Nasional "Veteran" Jawa Timur.

Asdak, C. (2002). "Hidrologi dan Pengolahan Daerah Aliran Sungai", Gajah Mada University Press, Yogyakarta.

Nurhayati, Indah. (2006). "Desalinasi Air Payau Dengan Membran Reverse Osmosi (RO) Tekanan Rendah." Environmental Engineering RTL Copyright @ 2005, by ITS Library. Nurhayati, I., Purwoto, S. (2014). "Pengolahan Air Payau Berbasis Kimiawi melalui Tekno Membran Reverse Osmosis (RO) Terpadukan dengan Koagulan dan Penukaran Ion." Prosiding Seminar Nasional Kimia, ISBN 978-602-0951-00-3, 169-177.

Nurhayati, I., \& Purwoto, S. (2014), The Combination of Coagulant Aid, Ion Exchanger, and Reverse Osmosis (RO) on Brackish Water Treatment" Journal of Natural Sciences Research 4(24), 26-30. 
Peraturan Menteri Kesehatan Republik Indonesia. (2017). Standar Baku Mutu Kesehatan Lingkungan Dan Persyaratan Kesehatan Air Untuk Keperluan Higiene Sanitasi, Kolam Renang, Solus Per Aqua, Dan Pemandian Umum: Permenkes RI No.32 Tahun 2017.

Purwoto, S. (2009), Desalinasi Air Payau Secara Ion Exchange dengan Treatmen Resin Sintetis" Jurnal Teknik WAKTU 7(01), 52-59.

Purwoto, S., Sutrisno, J., (2016), "Pengolahan Air Tanah Berbasis Treatment Ferrolite, Manganese Zeolite, dan Ion Exchange" Jurnal Teknik WAKTU-ISSN: 1412-1867; 14(2), 21-31.

Purwoto, S., Rusdiyantoro., Sembodo. P. B. (2018). "Using Coagulant Aid, Poly Polypropylene Sediment, Ferrolite, Manganese Greensand, Cation Resin, and Anion Resin in Modifield Water Treatment". Civil and Environmental Research, ISSN-2225$0514 ; 10(06), 1-5$.

Qasim, Syed, R. (2000). "Water Works Engineering Planning, Design, and Operation”. Texas: Chiang, Patel \& Yerby Inc.

Rachmah, N., dan Purwoto, S. (2014). "Efektifitas Penurunan Mn dan Total Coliform Pada Air Sumur Gali Berbasis Zeolit." Jurnal Tekni WAKTU-ISSN: 1412-1867 12(01), 1-7.

Rahmawati, N., dan Sugito. (2015). "Reduksi Besi (Fe) dan Mangan (Mn) Pada Air Tanah Menggunakan Media Filtrasi Manganese Greensand dan Zeolit Terpadukan Resin”. Jurnal Teknik WAKTU- ISSN: 1412-1867; 13(2), 63-71.

Taffarel, S. R., Rubio, J., (2010), "Removal of $\mathrm{Mn}^{2+}$ from aqueous solution by manganese oxide coated zeolite."Minerals Engineering 23(14): 1131-1138.

Utari, W. (n.d). "Efektifitas Karbon Aktif dalam Menurunkan Kadar Bilangan Peroksidasi dan Penjernihan Warna Pada Minyak Goreng Bekas." 